\title{
Manufacturing and Microstructural Characterization of Sintered Nickel Wicks for Capillary Pumps
}

\author{
Eduardo Gonçalves Reimbrecht ${ }^{a}$, Márcio Celso Fredel, Edson Bazzo, \\ Fernando M. Pereira \\ Departamento de Engenharia Mecânica, Universidade Federal de Santa Catarina \\ Florianópolis - RS, Brazil
}

Received: August 15, 1998; Revised: March 30, 1999

\begin{abstract}
Sintered nickel powder is proposed to be used as porous wicks in heat pipes and capillary pumps. In this work the manufacturing procedure for tubular wicks for capillary pump application is discussed. The porosity, mechanical resistance and roundness of tubular wicks made of carbonila powder, atomized powder and a powder mixture of both are analyzed. A powder mixture was selected as the best raw material. In this case, pore size in the range of 2 to $24 \mu \mathrm{m}$ and porosity about $50 \%$ were measured. First tests carried out in the laboratory, using acetone as the working fluid, show capillary pumping pressures up to $4 \mathrm{kPa}$ and heat fluxes of about $1 \mathrm{~W} / \mathrm{cm}^{2}$ in a two-phase heat transfer loop.
\end{abstract}

Keywords: sintered nickel powder, porosity analysis, wick characterization, capillary pump

\section{Introduction}

Wicking structures are currently used in heat pipes and capillary pumped loops. The main purpose of a wick is to generate the capillary pumping pressure required to transport a working fluid along a two-phase heat transfer loop. Typical wicking structures consists of grooved surfaces, wire meshes, screens and sintered metal powders ${ }^{1,2}$.

In general, heat pipes and capillary pumped loops (CPL's) are efficient two-phase heat transfer devices to transport thermal energy, even at a very small temperature difference, without any external power requirements to pump the working fluid. Both, the heat pipe and the CPL use capillary forces to pump the working fluid from heat acquisition systems to heat rejecting devices. A typical CPL is shown in Fig. 1. It consists of one capillary pump (evaporator), a vapor transport line, one condenser, a liquid transport line and a two phase fluid reservoir. Ammonia is usually selected as a working fluid.

Cold liquid is pumped from the condenser by capillary action of the wick. The wick structure in the loop is located inside the capillary pump. By applying heat load onto the capillary pump, the liquid evaporates and the vapor flows to the condenser through the vapor transport line. The reservoir is used for temperature control and initial priming of the evaporator ${ }^{3}$.

The selection of a wick depends mainly on the type of the working fluid and the required capillary action to pump

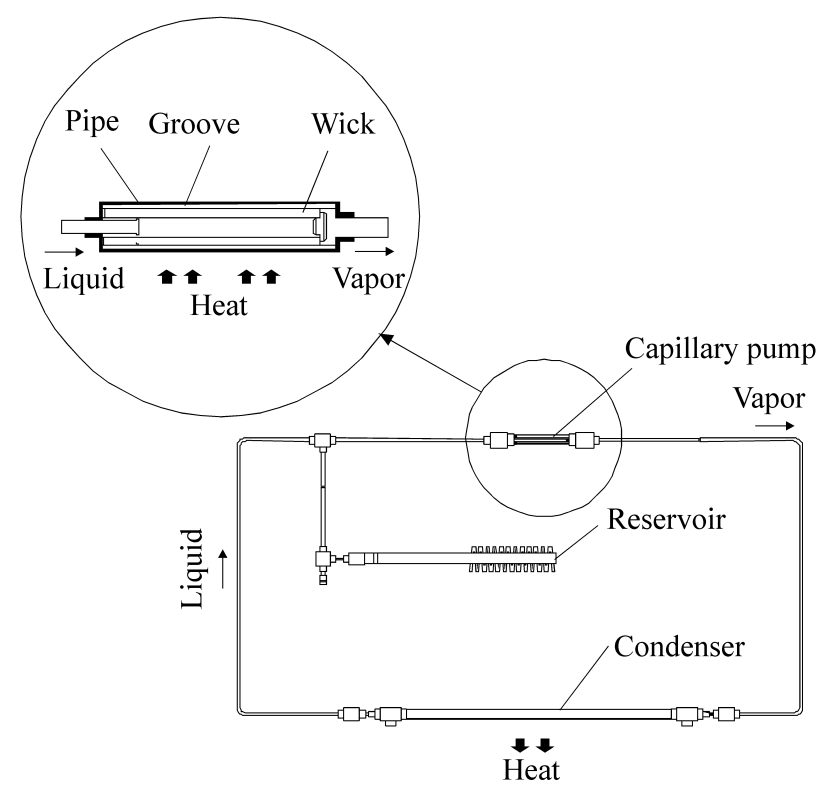

Figure 1. Schematic CPL.

a edurg@labmat.ufsc.br 
the liquid along the loop. Polyethylene, stainless steel, titanium and nickel are all compatible with ammonia and can be used as wicking structure. The capillary pumping pressure increases with decreasing pore size. However the wick permeability decreases with decreasing pore size. So, an optimal pore size for wicks has to be determined.

Polyethylene wicks have been currently specified with pores sizes in the range of 10 to $13 \mu \mathrm{m}$, generating pumping pressure up to $3 \mathrm{kPa}^{3}$. Sintered nickel has also been proposed as capillary structure, with pore sizes in the range of 1 to $12 \mu \mathrm{m}$ and porosity level of about $60 \%$. In that case, the corresponding capillary pumping pressures can vary from 3 to $40 \mathrm{kPa}^{4,5}$.

Several researches have been systematically performed for solving problems related to the operation of CPL's. Alternative projects and different types of materials are being used in order to improve the performance of the CPL's. Following this trend, researches are being also conducted at UFSC. More recently, a small scale CPL was scheduled to be tested aboard the French-Brazilian scientific satellite. The satellite is planned to be launched in the year $2001^{6}$. In this CPL, a capillary pump with a porous element of sintered nickel will be used.

The procedures for the production and characterization of the wick are presented here. In order to characterize the porous wick, the influence of different sintering parameters and powders on the porosity, mechanical resistance and roundness have been analyzed ${ }^{7}$. The distribution of pore sizes and porosity are analyzed in detail in this work, since they significantly influence the CPL's performance.

\section{Materials and Methods}

Nickel powder carbonila 123 (NP-123), atomized powder and a mixture of the two were used as raw materials. The nickel powder carbonila 123 was provided by Inco Co. (USA) with a particle size in the range of 3 to $7 \mu \mathrm{m}$ (specific surface area: $\left.0 ., 3-0.4 \mathrm{~m}^{2} / \mathrm{g}\right)^{8,9}$. The atomized powder has a particle size in the range of 25 to $45 \mu \mathrm{m}$. For the mixture, $73 \%$ of the atomized powder and $27 \%$ of NP-123 were used.

Following the literature ${ }^{9,10}$ for the manufacturing of the porous structures a tap powder sintering technique in a graphite matrix was used. Graphite is recommended by Fedorschenko ${ }^{10}$ and Thümmler ${ }^{11}$, because it shows a low interaction with nickel at the usual sintering temperatures. The matrix was designed taking into account the furnace volume and the dimensional characteristics of the capillary pump project.

The sintering process was conducted in a controlled-atmosphere-furnace Heraeus (ROK-F 7/60) with a commercial hydrogen flow of $1 \mathrm{~cm}^{3} / \mathrm{s}$. The selected sintering temperatures vary from 800 to $1050{ }^{\circ} \mathrm{C}$, in intervals of $50{ }^{\circ} \mathrm{C}$, during $30 \mathrm{~min}$. Each sintering temperature schedule was repeated at least four times, to increase data reliability for shrinkage, porosity and geometrical deviation of the cylindrical wicks.

The porosity of the wicks was geometrically determined measuring their mass $\mathrm{m}$, length $\mathrm{L}$, external diameter $\varnothing_{\mathrm{e}}$ and thickness S. For the measurements, an electronic scale Mars model A1600 (resolution: $0.01 \mathrm{~g}$ ) and a caliper (resolution: $0.05 \mathrm{~mm}$ ) were used. The volumetric fraction of pores was then calculated according to:

$$
\begin{aligned}
& \mathrm{Pg}=100\left(1-\frac{\rho}{\rho_{\mathrm{Ni}}}\right) \\
& \rho=\frac{4 \mathrm{~m}}{\pi \mathrm{L}\left(\phi_{\mathrm{e}}{ }^{2}-{\phi_{\mathrm{i}}}^{2}\right)}
\end{aligned}
$$

where, $\mathrm{Pg}$ is the volumetric fraction of pores of the wick $(\%), \varnothing_{\mathrm{i}}$ is the internal diameter $(\mathrm{cm}), \rho$ is the apparent specific mass $\left(\mathrm{g} / \mathrm{cm}^{3}\right)$ and $\rho_{\mathrm{Ni}}$ is the specific mass of nickel $\left(\rho_{\mathrm{Ni}}=8.9 \mathrm{~g} / \mathrm{cm}^{3}\right)$.

The porosity was also determined by the Arquimedes method according to:

$$
\begin{aligned}
& \mathrm{Pa}=100\left(1-\frac{\rho}{\rho_{\mathrm{Ni}}}\right) \\
& \rho=\frac{\mathrm{mg} \rho_{\mathrm{Hg}}}{E}
\end{aligned}
$$

where, $E$ is the thrust of the material immerged in mercury $\left(\rho_{\mathrm{Hg}}=13.6 \mathrm{~g} / \mathrm{cm}^{3}\right)$.

In order to get an appropriate fitting inside the capillary pump, the external diameter is the geometric parameter of the wick that must be strongly controlled. So the roundness was measured for each group of 4 samples submitted to the same sintering conditions. A total of ten measurements $\left(\varnothing_{j}\right)$, along every wick, were made to obtain a mean value for the diameter $\left(\phi_{m}\right)$. The roundness $(\lambda)$ was then determined from Eq. 5.

$$
\lambda=\frac{1}{n} \sum_{j=1}^{n}\left(\frac{\left|\phi_{i}-\phi_{m}\right|}{\phi_{m}}\right) 100
$$

where $n$ is the total number of measurements and $j=1$ to $n$.

The level of porosity, as well as its pore size distribution, are important parameters to be considered in wick manufacturing. As stated before, the capillary pumping pressure depends on these mentioned parameters. Both were measured on images acquired by an scanning electronic microscopy (SEM) from a set of samples prepared in the laboratory. An Imago-software developed by LMPT/UFSC (Laboratório de Meios Porosos e Propriedades Termofísicas de Materiais) and ESSS (Engineering Simulation and Scientific Software) was utilized. The 
method is based on a comparison of pore images with an octagonal pattern. After each comparison, the pattern's radius is increased and a new scanning is made. The procedure is repeated until no pores are detected and a cumulative pore size distribution curve is built.

\section{Results and Discussion}

The first step for the manufacture of a wick was to identify the optimal sintering parameters with respect to time and temperature. Preliminary assembling tests showed that the most appropriate sintering time is $30 \mathrm{~min}$, resulting in sufficient mechanical resistance of the pieces without densification of the samples ${ }^{12}$. These results, together with additional literature information, makes it possible to determine a suitable sintering temperature range ${ }^{8,9}$.

The porosity values were measured by the geometric and Arquimedes methods, at different sintering temperatures (range $800{ }^{\circ} \mathrm{C}$ to $1050{ }^{\circ} \mathrm{C}$, at intervals of $50{ }^{\circ} \mathrm{C}$ ), and holding time of $30 \mathrm{~min}$. The porosity values are plotted in Figs. 2 and 3 for the three different types of powder employed.

As expected, the results are similar for both methods. The higher the sintering temperature the smaller the porosity. It was also observed a relatively higher porosity level for the NP-123 than for the mixture of powders and for the atomized powder wicks. For NP-123 a porosity level in the range of 55 to $66 \mathrm{vol} . \%$ was found, although they showed a high dependence on the sintering temperature.

Wicks made from atomized powder presented the lowest porosity level. As a consequence of the raw material particle size used here, the mean pore size is expected to be higher. Low porosity associated to large pore sizes generate a very weak capillary pumping pressure head. So the atomized powder is not recommended for capillary pumps. Additionally, the shrinkage is insufficient to allow an easy extraction of sintered atomized powder wicks from the mold.

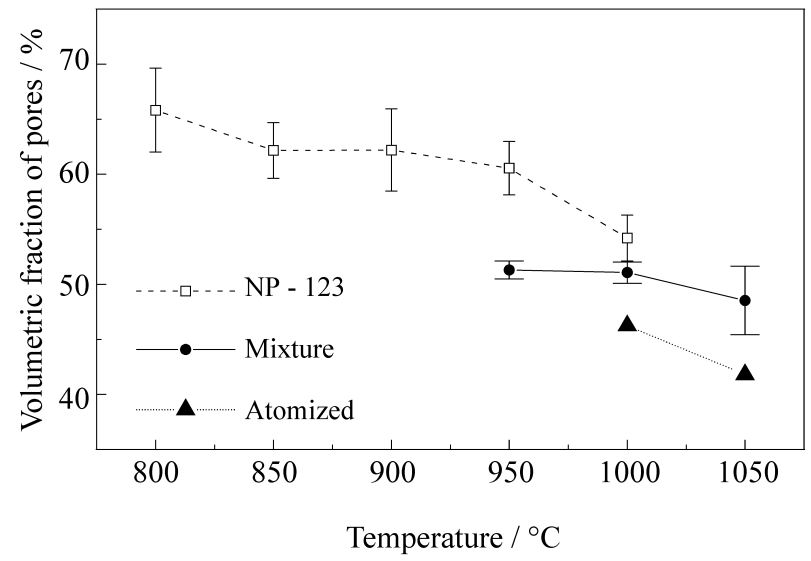

Figure 2. Porosity values Volumetric fraction of pores measured by the geometric method for different types of Ni-powders.

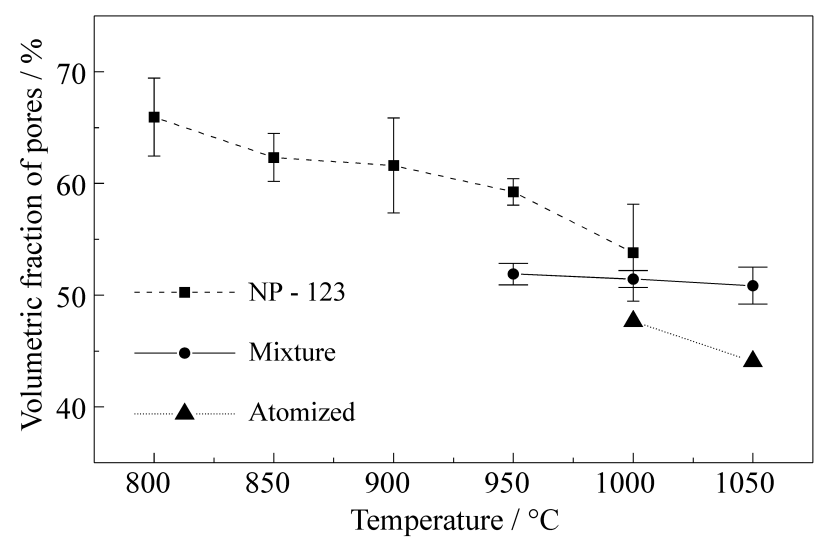

Figure 3. Porosity values Volumetric fraction of pores measured by the Arquimedes method for different types of Ni-powders.

For the mixture of powders, a porosity level around $50 \mathrm{vol} . \%$ was measured. In this case, it is expected that the fine NP-123 particles will fill existing voids in the arrangement of the atomized powder particles.

Another important parameter considered is the wick roundness. The used powder mixture gives better shape retention during sintering, with a resulting lower roundness compared to the NP-123. This can be observed in Fig. 4.

The higher roundness of the wicks produced from the NP-123 (approximately 5\%) makes it impossible to fit them inside the grooved aluminum tube. The higher the roundness of the wick the higher the gaps between the grooved tube and the wick. For capillary pumps applications no gaps are desirable, since they increase the thermal resistance, reducing the heat transfer and the vapor formation. For the powder mixture wicks, a very weak sintering temperature dependence and an acceptable roundness of about only $2 \%$ have been observed.

The factors that determined the optimum sintering parameters were porosity, mechanical resistance and roundness. Although high porosity is advantageous for use in capillary pumps, this implies in a lower mechanical resistance. In this work, the mechanical resistance was not

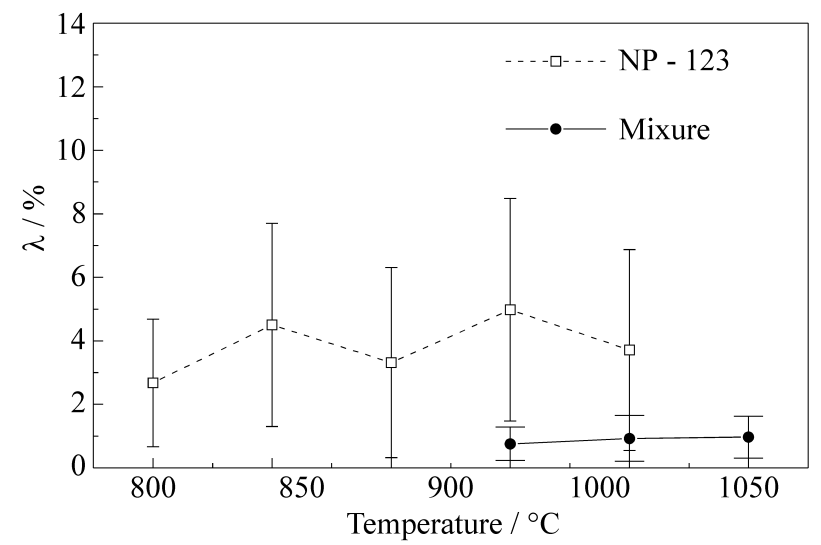

Figure 4. Wick roundness measured for NP-123 and mixture of powders. 
measured directly. It was assumed that the wick have a satisfactory mechanical resistance if it supports the compressive efforts during the assembly of the capillary pump. So, the best set of sintering parameters were obtained at $950{ }^{\circ} \mathrm{C}$ for $30 \mathrm{~min}$.

Figure 5 presents the pore size distribution curves for the three different powders used. As expected from the raw materials characteristics, the NP-123 showed the lowest mean pore size value $\left(\mathrm{D}_{50}=5 \mu \mathrm{m}\right)$ compared to the atomized powder wick $\left(D_{50}=17 \mu \mathrm{m}\right)$ and the mixture $\left(\mathrm{D}_{50}=8 \mu \mathrm{m}\right)$. Another interesting information that can be visualized in Fig. 5 is the pore size range, from 1 to $20 \mu \mathrm{m}$ for the NP-123, from 4 to $37 \mu \mathrm{m}$ for the atomized and from 2 to $24 \mu \mathrm{m}$ for the powder mixture.

A better insight into the pore structure can be reached by analyzing the cumulative pore size distribution, where clusters and voids can still be identified in the structure, see Fig. 6. Figure 7 shows a pore size distribution as well as the cumulative pore distribution for the powder mixture wick. According to the cumulative pore size distribution curve, at least $90 \mathrm{vol} . \%$ of the pores have less than $16 \mu \mathrm{m}$. That is a good indication of the quality of the wick, since the smaller the pore size the higher the capillary pumping pressure. In addition, it is impor-

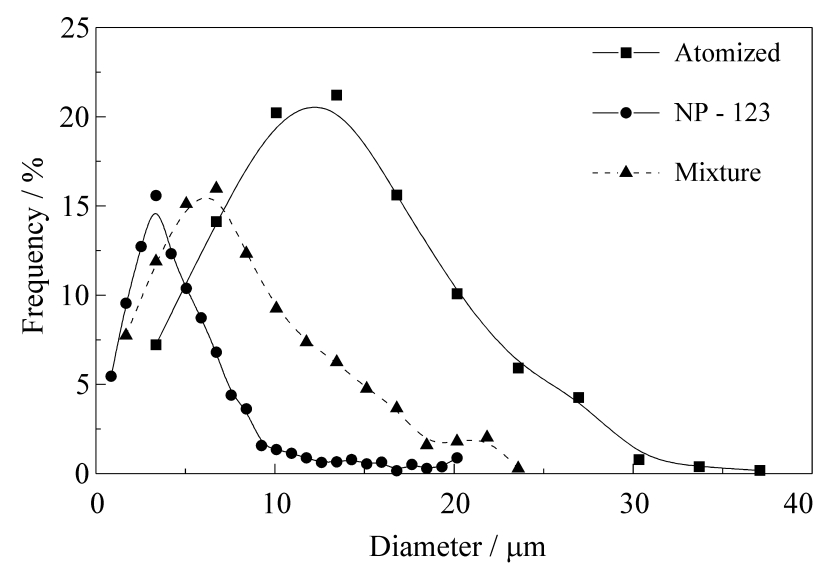

Figure 5. Pore size distribution curves for the three types of powders.

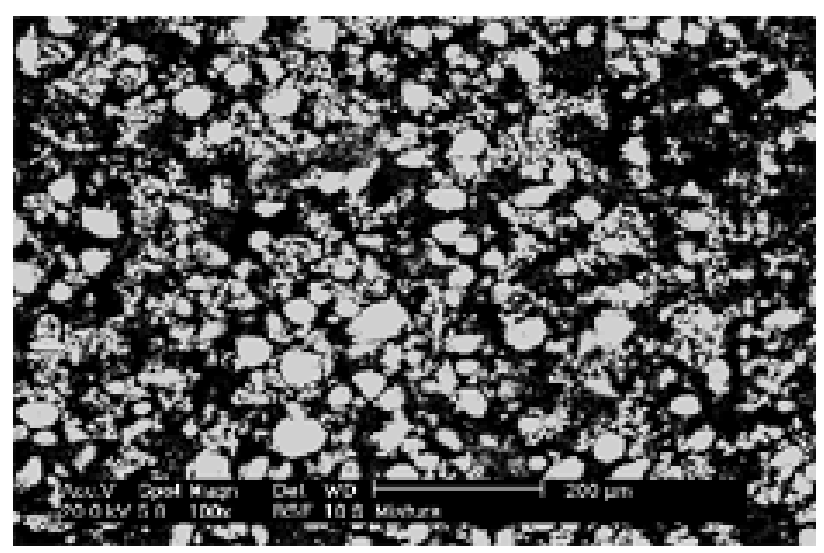

Figure 6. Micrography of the sintered powder mixture, obtained by SEM.
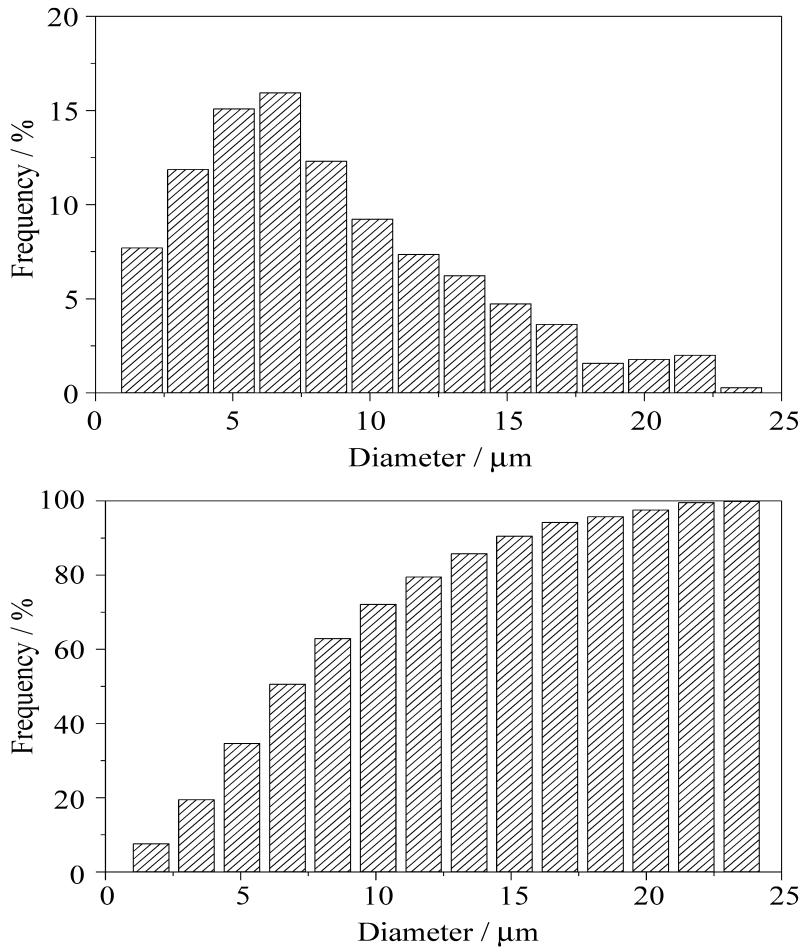

Figure 7. Standard and cumulative pore size distribution for sintered powder mixture.

tant to observe that the largest interconnected pores will determine the capillary pressure.

As a consequence of the above evaluation, it was found that the powder mixture is the most suitable raw material for the production of sintered Ni-wicks. Mixture powder wicks presented a satisfactory capillary pumping pressure and an acceptable roundness for using in capillary pumps. First tests carried out in the laboratory, using acetone as the working fluid, demonstrated heat fluxes of about $1 \mathrm{~W} / \mathrm{cm}^{2}$ and capillary pressures up to $4 \mathrm{kPa}$.

\section{Conclusions}

Nickel powder carbonila 123, atomized powder and a mixture of the two were used as raw materials for the production of capillary structures. The best results were obtained using a mixture of $73 \%$ vol. atomized / $27 \%$ vol. carbonila powders.

The powder mixture presented a satisfactory porosity level ( $50 \%$ ), good mechanical resistance and low roundness for using in capillary pumps. An electronic image analyzer was used to characterize the pores showing a accumulative pore size distribution with a $\mathrm{D}_{90}$ value $16 \mu \mathrm{m}$.

Further experiments are also planned for other geometry wicks, in order to improve the performance of the capillary pumps for space application. 


\section{Acknowledgment}

The authors knowledge prof. Aloísio M. Klein and Paulo A.P. Wendhausen, from Labmat, Paulo C. Philippi, José A. Bellini da Cunha and Celso P. Fernandes, from LMPT, for supporting this work.

\section{References}

1. Peterson, G.P. An Introduction to Heat Pipes; Modeling, Testing and Applications, John Wiley \& Sons. Inc., New York, 1994.

2.Dunn, P.D.; Reay, D.A. Heat pipes, Pergamon Elsevier Science Ltd., $4^{\text {th }}$ Edition, London, 1994.

3. Jentung, Ku. Overview of Capillary Pumped Loop Technology, The 29th National Heat Transfer Conference, Atlanta, Georgia, August 8-11, HTD, v. 236, 1993.

4. Goncharov, K., et al. Loop Heat Pipes in Thermal Control System for Spacecraft, 28th International Conference on Environmental Systems, San Diego, July 10-13, 1995.

5. Maidanik, Y.U.F.; Fershtater, Y.U.G.; Goncharov, K.A. Capillary-pump Loop for Systems of Thermal Regulation of Spacecraft, 4th European Symposium on Space Environmental and Control Systems, Florence, October 21-24, 1991.
6. Bazzo, E.; Mantelli, M.B.H. Study of Design Parameters of a Small Scale CPL, $28^{\text {th }}$ International Conference on Environmental Systems, Paper n. 981690, Danvers, Massachusetts, July 13-16, 1998.

7. Watwe, A.S.; DeHoff, R.T. Metric and Topological Characterization of the Advanced Stages of Loose Stack Sintering Metallurgical Transactions A, v. $21^{\mathrm{A}}$, p. 2935-2941, 1990.

8. Tracey, V.A. Pressing and Sintering of Nickel Powders, The International Journal of Powder Metallurgy \& Powder Technology, v. 20, n. 4, p. 281-285, 1984.

9. Tracey, V.A. Sintering of Porous Nickel - Theoretical and Practical Considerations. Modern Developments in Powder Metallurgy, v. 12, p. 423-438, 1981.

10. Fedorchenko, I.M. Progress in Work in the Field of High-Porosity Materials From Metal Powders and Fibers, Plenum Publishing Corporation, p. 615-622, 1980.

11. Thümmler, F.; Oberacker, R. Introduction to Powder Metallurgy, London: The Institute of Materials Carlton House Terrace London, 1993.

12. Reimbrecht, E.G.; Fredel, M.; Bazzo, E. Fabricação de Elementos Porosos para Utilização em Bombas Capilares, paper presented at 13 CBECIMAT, Curitiba, 1998. 